\title{
ANALISIS TINGKAT KOMPETENSI DOSEN STMIK DHARMASRAYA DENGAN MENGGUNAKAN METODE PREFERENCE RANKING ORGANIZATION METHOD FOR ENRICHMENT EVALUATION (PROMETHEE)
}

\author{
Wahyu Prima1), Beni Putra ${ }^{2)}$ \\ ${ }^{1}$ Fakultas Ilmu Komputer, Universitas Dharmas Indonesia, Dharmasraya \\ ${ }^{2}$ Fakultas Ilmu Komputer, Universitas Dharmas Indonesia, Dharmas raya \\ email: wahyuprima341@gmai.com¹, beniputra237@gmail.com²
}

\begin{abstract}
Abstrak
Penelitian ini dilakukan untuk menganalisis tingkat kompetensi dosen STMIK Dharmasraya (Sekarang Menjadi Fakultas Ilmu Komputer Universitas Dharmasraya) yang selama ini dilakukan secara manual, yaitu dengan cara melakukan wawancara dengan mahasiswa, tenaga kependidikan, dosen, ketua program studi, dan ketua. Data dikumpulkan melalui studi lapangan/wawancara dan studi pustaka yang kemudian dirancang menjadi bentuk kuisioner. Selanjutnya data dianalisis dengan menggunakan metode Preference Ranking Organization Method for Enrichment Evaluation (Promethee). Melalui metode Promethee, tingkat kompetensi dosen Fakultas Ilmu Komputer Universitas Dharmas Indonesia dapat dilihat. Sistempendukung keputusan dengan menggunakan metode ini diharapkan menghasilkan keputusan yang dapat dipertanggungjawabkan akuntabilitasnya. Berdasarkan hasil analisis melalui metode Promethee diperoleh hasil bahwa alternatif A4 memperoleh peringkat pertama dengan net flow sebesar 0,8750; A3 memperoleh peringkat kedua dengan net flow sebesar 0,1259; A2 memperoleh peringkat ketiga dengan net flow sebesar 0,0625; A5 memperoleh peringkat keempat dengan net flow sebesar-0,0625; A1 memperoleh peringkat kelima dengan net flow sebesar -1,0000.
\end{abstract}

Keywords: Metode Promethee dan Kompetensi Dosen

\section{PENDAHULUAN}

Undang-Undang Republik Indonesia Nomor 20 Tahun 2003 Tentang Sistem Pendidikan Nasional merumuskan fungsi dan tujuan pendidikan nasional yang harus digunakan dalam mengembangkan pendidikan di Indonesia. Pasal 3 menyebutkan bahwa "Pendidikan nasional berfungsi mengembangkan kemampuan dan membentuk watak serta peradaban bangsa yang bermartabat dalam rangka mencerdaskan kehidupan bangsa, bertujuan untuk berkembangnya potensi peserta didik agar menjadi manusia yang beriman dan bertakwa kepada Tuhan Yang Maha Esa, berakhlak mulia, sehat, berilmu, cakap, kreatif, mandiri, dan menjadi warga negara yang demokratis serta bertanggung jawab"(Pemerintah Republik Indonesia, 2003).

Berdasarkan dari rumusan fungsi dan tujuan pendidikan nasional dapat disimpulkan bahwa pengembangan pendidikan nasional mengupayakan terbentuknya rakyat Indonesia yang bermutu dan memiliki karakter sifat serta budi pekerti yang baik. Selain membentuk karakter yang baik, tujuan pendidikan nasional juga membentuk rakyat yang kreatif, dan madiri. Salah satu upaya terwujutnya tujuan pendi-dikan nasional dapat dicapai dengan meningkatkan kompetensi tenaga pendidik salah satunya adalah dosen.

Undang-Undang Republik Indonesia Nomor 14 Tahun 2005 Tentang Guru dan Dosen Pasal 1 ayat 2 menyebutkan bahwa dosen adalah pendidik profesional dan ilmuwan dengan tugas utama mentransformasikan, mengembangkan, dan menyebarluaskan ilmu pengetahuan, teknologi, dan seni melalui pendidikan, penelitian, dan pengabdian kepada masyarakat. Untuk tercapainya rumusan undang-undang di atas maka perlunya peningkatan kompetensi dosen. Pasal 69 ayat 2 menyebutkan bahawa" Pembinaan dan pengembangan profesi dosen sebagaimana dimaksud pada ayat 1 meliputi kompetensi pedagogik, kompetensi kepribadian, kompetensi sosial, dan kompetensi profesional'(Pemerintah Republik Indonesia, 2005).

Berdasarakan pasal diatas maka dibutuhkan analisa tentang tingkat kompetensi dosen agar dapat mengukur tingkat kompetensi dosen 
serta dapat sebagai bahan pertimbangan evaluasi diri bagi para dosen. Seperti halnya penilaian kompetensi dosen di Fakultas Ilmu Komputer Universitas Dharmas Indonesia yang selama ini hanya ilakukan secara manual, yaitu dengan cara melakukan wawancara dengan mahasiswa, tenaga kependidikan, dosen dan dekan. Oleh karena itu diperlukan suatu sistem yang dapat diguanakan untuk menganalisis tingkat kompetensi dosen. Banyak metode yang dapat membatu dalam analisa ini diantaranya metode Preference Ranking Organization Method for Enrichment Evaluation (Promethee)

Promethee merupakan metode untuk penyelesaian masalah pengambilan keputasan yang termasuk ke dalam kategori MADM (Multiple Attribute Decision Making) yang dikembangkan oleh J.P Brans (Murat, Kazan, \& Coskun, 2015; Polat, Damci, Gurgun, \& Demirli, 2016).

Promethee merupakan suatu metode penentuan urutan (prioritas) yang lebih sederhana dalam analisa multikriteria, lebih jelas dalam perhitungan dan proses analisanya, stabil serta lebih mudah dipahami. Sehingga diharapkan dapat menjadi solusi bagi permasalahan dalam menganalisis tingkat kompetensi dosen di lingkungan Fakultas Ilmu Komputer Universitas Dharmas Indonesia.

\section{METODE PENELITIAN}

Adapun kerja penelitian dari penelitian ini dapat dilihat pada Gambar 1.

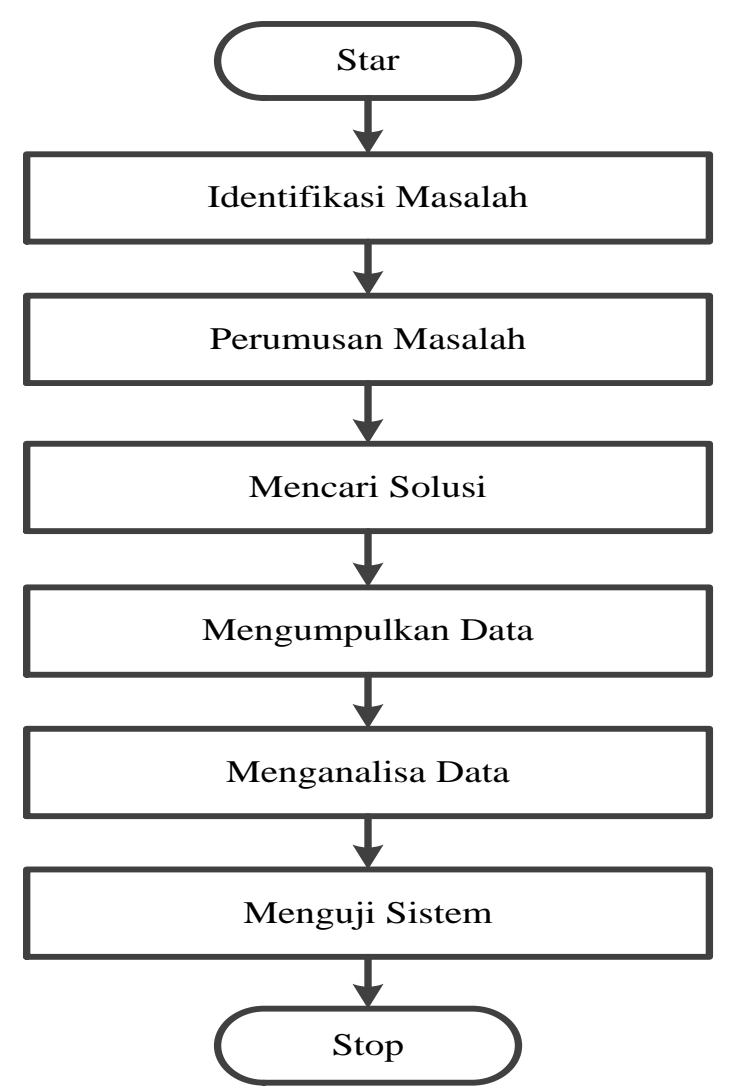

Gambar 1. Kerangka Kerja Penelitian

\section{HASIL DAN PEMBAHASAN}

Analisis data dilakukan dengan beberapa tahapan sebagai berikut: 1) Analisis Kebutuhan; 2) Analisis penggunan metode Promethee; 3) Pengujian dengan software visual promethee.

\section{Analisis Kebutuhan}

Dalam analisis kebuthan ini peneliti melakukan beberapa anaisis kebutuhan sebagai berikut: 1) Analisis kebutuhan kriteria; 2) Analisis kebutuhan alternatif; 3) Analisis kebutuhan kriteria dan pengkodean; 4) Analisis kebutuhan responden; 5) Analisi kebutuhan perangkat. Proses analisis kebutuhan dapat dilihat pada Tabel 1 dan 2.

Tabel 1. Pengkode an Alte rnatif

\begin{tabular}{cc|c}
\hline No & Alternatif (Inisial) & Kode \\
\hline 1 & ADP & A1 \\
2 & GNA & A2 \\
3 & FRP & A3 \\
4 & EPR & A4 \\
5 & WPI & A5 \\
\hline
\end{tabular}


Tabel 2. Tabel Skenario Pembobotan Krite ria dan Pengkodean

\begin{tabular}{|c|c|}
\hline Kriteria & Deskripsi \\
\hline 1. Kompetensi & Kode f1 \\
\hline Pedagogik & $\begin{array}{ll}\text { 1. } & \text { Sangat tidak baik } \\
\text { (Bobot 1) } \\
\text { 2. } & \text { Tidak baik } \\
\text { (Bobot 2) } \\
\text { 3. } & \text { Biasa (Bobot 3) } \\
\text { 4. } & \text { Baik (Bobot 4) } \\
\text { 5. } & \text { Sangat Baik } \\
& \text { (Bobot }\end{array}$ \\
\hline 2. Kompetensi & Kode $\mathrm{f} 2$ \\
\hline Kepribadian & $\begin{array}{l}\text { 1. Sangat tidak baik } \\
\text { (Bobot 1) } \\
\text { 2. Tidak baik } \\
\text { (Bobot 2) } \\
\text { 3. Biasa (Bobot 3) } \\
\text { 4. Baik (Bobot 4) } \\
\text { 5. Sangat Baik } \\
\text { (Bobot 5) }\end{array}$ \\
\hline 3. Kompetensi & Kode $\mathrm{f} 3$ \\
\hline Sosial & $\begin{array}{ll}\text { 1. } & \text { Sangat tidak } \\
\text { baik (Bobot 1) } \\
\text { 2. } & \text { Tidak baik } \\
& \text { (Bobot 2) } \\
\text { 3. } & \text { Biasa (Bobot 3) } \\
\text { 4. } & \text { Baik (Bobot 4) } \\
\text { 5. } & \text { Sangat Baik } \\
& \text { (Bobot }\end{array}$ \\
\hline 4. Kompetensi & Kode $\mathrm{f} 4$ \\
\hline Profesional & $\begin{array}{l}\text { 1. Sangat tidak baik } \\
\text { (Bobot 1) } \\
\text { 2. Tidak baik (Bobot } \\
\text { 2) } \\
\text { 3. Biasa (Bobot 3) } \\
\text { 4. Baik (Bobot 4) } \\
\text { 5. Sangat Baik } \\
\text { (Bobot }\end{array}$ \\
\hline
\end{tabular}

2. Analisis Penggunaan Metode Promethee Berdasarkan data yang dikumpulkan dengan analisis kebutuhan, data diinputkan data desar dari nilai kriteria dari masingmasing alternatif untuk dievaluasi dengan menggunakan metode promethee sebagai mana tertera pada Tabel 3 .

Tabel 3. Nilai Krite ria Tiap Alternatif

\begin{tabular}{cccccccc}
\hline $\begin{array}{c}\text { Krit } \\
\text { eria }\end{array}$ & $\begin{array}{c}\text { Max } \\
\text { Max }\end{array}$ & $\mathbf{A}_{\mathbf{1}}$ & $\mathbf{A}_{\mathbf{2}}$ & $\mathbf{A}_{\mathbf{3}}$ & $\mathbf{A}_{\mathbf{4}}$ & $\mathbf{A}_{5}$ & $\begin{array}{c}\text { Tip } \\
\mathbf{e}\end{array}$ \\
\hline $\mathbf{f}_{\mathbf{1}}()$. & $\operatorname{Max}$ & 3,29 & 4,52 & 4,59 & 4,77 & 4,66 & $\mathrm{I}$ \\
$\mathbf{f}_{\mathbf{2}}()$. & $\operatorname{Max}$ & 3,40 & 4,43 & 4,60 & 4,60 & 4,50 & $\mathrm{I}$ \\
$\mathbf{f}_{\mathbf{3}}()$. & $\operatorname{Max}$ & 3,64 & 4,69 & 4,67 & 4,69 & 4,50 & $\mathrm{I}$ \\
$\mathbf{f}_{\mathbf{4}}()$. & $\operatorname{Max}$ & 4,10 & 4,78 & 4,77 & 4,87 & 4,77 & $\mathrm{I}$ \\
\hline
\end{tabular}

3. Pengujian dengan Software visual Promethee

Pada tahap ini dibutuhkan data nilai kriteria tiap alternatif yang akan diinputkan kedalam software promethe yang terdapat pada tabel 3 .

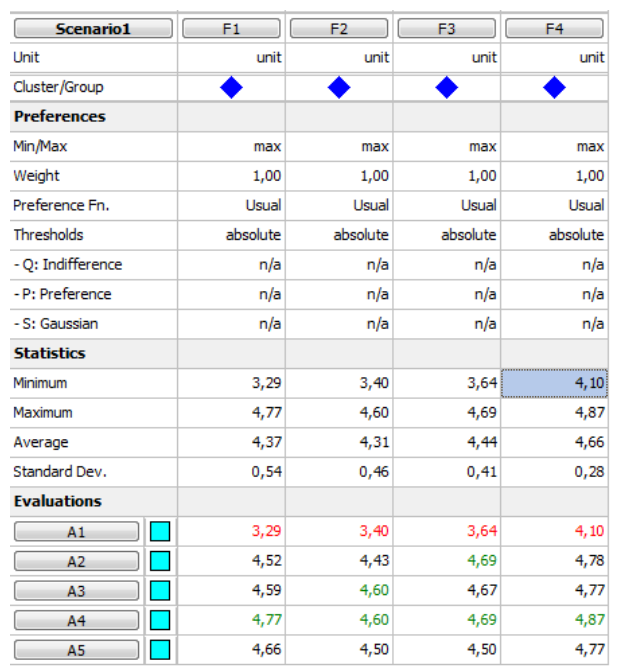

Gambar 2. Nilai Krite ria Setiap Alte rnatif

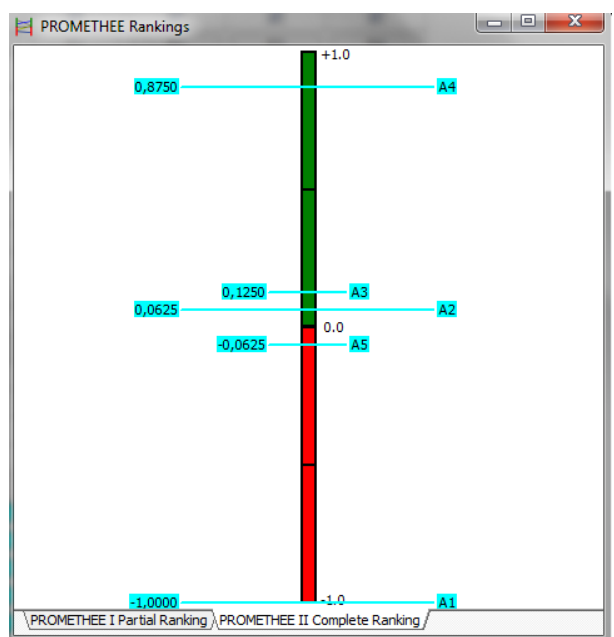

Gambar 3. Hasil Rankng Promethee II

Berdasarkan Gambar 3 terlihat bahwa alternatif A4 memperoleh peringkat pertama dengan net flow sebesar 0,8750; A3 memperoleh peringkat kedua dengan net flow sebesar 0,1259; A2 memperoleh peringkat ketiga dengan net flow sebesar 0,0625; A5 memperoleh peringkat keempat dengan net flow sebesar -0,0625; A1 memperoleh peringkat kelima dengan net flow sebesar 1,0000 .

\section{SIMPULAN}

Dengan diterapkannya metode preference ranking organization method for 
enrichment evaluation (Promethee) dalam analisis tingkat kompetensi dosen Fakultas Ilmu Komputer Universitas Dharmas Indonesia dapat disimpulkan bahwa hasil alternatif A4 memperoleh peringkat pertama dengan net flow sebesar 0,8750; A3 memperoleh peringkat kedua dengan net flow sebesar 0,1259; A2 memperoleh peringkat ketiga dengan net flow sebesar 0,0625; A5 memperoleh peringkat keempat dengan net flow sebesar -0,0625; A1 memperoleh peringkat kelima dengan net flow sebesar 1,0000 .

\section{UCAPAN TERIMAKASIH}

Terimakasih penulis ucapkan kepada Ditjen Penguatan Riset dan Pengembangan kementrian Riset, Teknologi, dan Pendidikan Tinggi yang memberikan dana hibah penelitian serta Lembaga Penelitian dan Pengabdian Masyarakat Universitas Dharmas Indonesia.

\section{DAFTAR PUSTAKA}

Murat, S., Kazan, H., \& Coskun, S. S. (2015). An Application for Measuring Performance Quality of Schools by Using the PROMETHEE Multi-Criteria Decision Making Method. Procedia Social and Behavioral Sciences, 195, 729-738.

https://doi.org/10.1016/j.sbspro.2015.06. 344

Pemerintah Republik Indonesia. UndangUndang Republik Indonesia Nomor 20 Tahun 2003 Tentang Sistem Pendidikan Nasional, Produk Hukum $§ ~(2003)$.

Pemerintah Republik Indonesia. UndangUndang Republik Indonesia Nomor 14 Tahun 2005 tentang Guru dan Dosen, Produk Hukum § (2005).

Polat, G., Damci, A., Gurgun, A. P., \& Demirli, I. (2016). Urban Renewal Project Selection Using the Integration of AHP and PROMETHEE Approaches. Procedia Engineering, 164, 339-346. https://doi.org/10.1016/j.proeng.2016.11. 628 